\title{
UNA ClASIFICACIÓN PERCEPTIVA dE LA CATEgORÍA VERBO
}

\author{
Montserrat Veyrat Rigat \\ Universitat de València \\ montserrat.veyrat@uv.cs
}

\begin{abstract}
Resumen
The verb caterogy has received different and varied descriptions and explanations throughout the history of the study of language. This paper starts by accounting for the basic postulates of a perceptive framework. This language explanatory framework is philosophically grounded in Fenomenology and, according to it, language exists not merely as an object of autonomous study, but the said object is constructed gradually, as the researcher becomes conscious of it. Next, the paper elaborates on the perceptive fundamentals that allow us to consider the verb category as a pcrceptive universe with an inner space, an outcr space, boundaries and a dynamic space of adherence. The functions that verbs serve in Spanish and in many other languages (auxiliary and main functions) are distributed in these spaces. Finally, following these critera the paper proposes a classification of the verbs of our language laking into consideration their function as main or auxiliary verbs.
\end{abstract}

\section{Planteamiento de ta Lingǘstica Pereleptiva ${ }^{1}$}

Un enfoque perceptivo para cl conocimiento de cualquier objeto de nuestro entorno sostendria que podemos describirlo en sí mismo y por sí mismo, dado que tiene existencia propia e independiente. Una mesa, por ejemplo, desde nucstro punto de vista de usuarios observadores, será para nosotros un mueble que reunirá unas condiciones y cumplirá unas funciones determinadas, esto es, tendrá una o varias patas, dispondrá de un tablero realizado con un material resistente, su diseño será moderno o clásico, servirá para ap̧oyarnos o para comer, etc. Los rasgos descriptivos que le atribuyamos variarán cn relación al tipo de usuario que seamos: el carpintero, el mucblista, el ama de casa, el tapicero...

En este sentido, cuando consideramos el lenguajc como un objeto de estudio autónomo, estamos adoptando una actitud de usuarios observadores, y entonces el lenguaje es algo que nos viene dado para ser estudiado como objeto en sí mismo. Mediante su observación podcmos describirlo, analizarlo en sus componentes, descubrir sus funciones en relación al usuario, podemos comparar las distintas manifestaciones del lenguaje en las distintas lenguas, e incluso en una misma lengua. El investigador se sitúa frente a su objeto de estudio y lo analiza, lo describe, intenta construir su gramática, sus reglas de funcionamicnto, establecer las relaciones entre sus unidades... Y su descripción varía en función de las

1 Una versión previa de este estudio se puede encontrar en http://www.um.es/tonosdigital. El trabajo que aquí se presenta supone una revisión de la clasificación vcrbal que allí se realiza en los espacios de adherencia y fronterizo. 
necesidades expositivas del investigador. De ahí la enorme variedad de revisiones que ha recibido la categoría verbo desde los primeros momentos de preocupación por la explicación y descripción de las lenguas. Una bucna muestra de ello lo constituye la propia obra en la que se inscribe este trabajo.

Sin embargo, un enfoque de naturaleza cognitivista sostiene que al mismo tiempo que cl lenguaje es algo que nos viene dado y existe de manera autónoma para ser estudiado, también es algo propio del ser humano, es consustancial a ćl, y debido a esto, el hombre (tanto si es un simple usuario como si es un gramático) dispone de un saber natural, un saber previo que le faculta para utilizarlo y para construir explicaciones y descripciones de él.

El lenguaje, pues, no es sólo un objeto de estudio en si mismo, algo que existe con independencia del observador, sino que además es un fenómeno del que no podemos sustraernos porque forma parte del sujeto hablante, y por ello requiere el estudio de las relaciones cxistentes entre el sujeto hablante y el lenguaje en tanto objeto. En este sentido, también los objetos del mundo reciben un tratamiento semejantc: sería como si para hablar de la mesa mencionada más arriba no pudiéramos desprendernos de nuestra condición de usuarios y por ello la descripción, el análisis y crítica de su diseño, sus materiales, su funcionalidad... estuviera gobernada por nuestra actitud y necesidades de usuarios.

La Lingüistica Perceptiva asume los postulados fenomenológicos como parte de sus fundamentos básicos, según los cuales aquellos rasgos o características que pertenecen al objeto independientemente de nuestra relación con él, pueden ser atendidos de una manera autónoma, pero además es preciso considcrar que los objetos son objetos siempre para alguien, y cn ese caso, aquello que el objeto adquiere sólo en su relación con nosotros, pertenece a esa caracterización del objeto que lo tiñe de matices novedosos y, en apariencia, exclusivos de nuestras vivencias con respecto a él.

Por otra parte, no podemos dejar de considerar la enorme complejidad del lenguaje, pues su multidimensionalidad nos atañe en un alto grado, hasta el punto que es imposible reducir todos sus aspectos a uno sólo que los abarque todos: nos encontramos ante un fenómeno que tiene dimensión física, pues es un producto fónico, visual y gráfico, pero al mismo tiempo también tiene una dimensión fisiológica, es perceptible, es de naturaleza psicológica, sociológica, neurológica, tiene capacidad creativa, es un objeto histórico, se caracteriza por ser autorreferencial, semiológico, es un sistema organizado... etc.

Precisamente por esta pluridimensionalidad, resulta imposible adoplar simultáneamente todas las perspectivas descle las que se puede hablar de él y se hace necesario seleccionar aquella más adecuada a nuestros deseos e intenciones para explicar sus propiedades esenciales. No obstantc, desde el momento en que se adopta un determinado punto de vista, se seleccionan unos aspectos de la realidad y se sitúan otros en scgundo plano, aquellos que no se consideran prioritarios, $\mathrm{c}$ incluso se ocultan algunos que por este motivo resultan inaccesibles a la observación.

Es innegable que cualquier perspectiva adoptada nos proporcionará una visión incompleta - parcial - de nuestro objeto de estudio, pero también es cierto que unos puntos dc vista pueden brindarnos descripciones preferibles a otras, bien porque nos presentan un panorama más amplio, bien porque nos permiten un enfoque más detallado, bien porque eluden la interferencia de fenómenos secundarios, o bien incluso porque inevitablemente se corresponden mejor con nuestros intereses descriptivos y/o explicativos. Por lo tanto, nos atrevemos a afirmar que no hay enfoques verdaderos y enfoques falsos, sino que antes bien 
unos serán más adecuados que otros dependiendo de la rentabilidad de su aplicación a los hechos que está explicando.

Tradicionalmente en nuestra disciplina viene sucediendo que los defensores de una determinada orientación contrastan sus enfoques con los de otra sin que cllo suponga en definitiva un verdadero avance o progreso científico en el sentido kuhniano. En realidad los modelos lingüísticos actualmente dominantes en el estudio, descripción y explicación del lenguaje (a saber, Funcionalismo, Generativismo y Cognitivismo) rcsponden cada uno de ellos a una actitud ante el objeto de estudio, y ninguno de ellos anula la validez de los demás, ya que en realidad obedecen a intereses e intenciones diferentes en el investigador ${ }^{2}$.

La perspectiva funcionalista considera que el lenguaje es un instrumento de comunicación y sus estudios encabezan el enfoque pragmático y comunicativo de la facultad lingüística y la concreción de esta en las distintas lenguas existentes en el mundo. El enfoque generativista por su parte califica el lenguaje como un sistema propio de todo ser humano que éste utiliza como un reflejo de la estructura mental de naturaleza cognitiva, por lo que sus preocupaciones se centran en formalizar ese sistema para explicitar sus reglas de funcionamiento. Por último, el cognitivista piensa que el lenguaje es un sistema de conocimiento con el que nos representamos las escenas del mundo y con el que clasificamos nuestras vivencias y sus componentes, por lo que sus prioridades se dirigen fundamentalmente al desarrollo de la semántica. A partir de estas consideraciones, parece adecuado y conveniente considerar las aportaciones que esos modelos lingüísticos realizan sobre el lenguaje como estudios parciales que responden tan sólo a una parte de la verdad, sin olvidar que tan aceptable es lo que se afirma desde el funcionalismo, como desde el generativismo o desde el cognitivismo ${ }^{3}$.

En resumen, nos enfrentamos a un fenómeno complejo y multidimensional cuya descripción y explicación requiere la integración racional de las distintas aproximaciones que hasta el momento han aportado conocimiento sobre él. Lo más urgente ahora es proveemos de un instrumento teórico-metodológico que nos suministre una base epistemológica ajustada a esta finalidad. Indudablemente una herramienta apropiada facilita enormemente una tarea como la que nos planteamos emprender siguiendo los presupuestos de la Lingüística Perceptiva, sin olvidar que el valor de una teoría está en relación directa a su grado de adecuación a los hechos que describe.

Eugcnio Coseriu (1981) considera que lo específico del lenguaje es cl cstar gobernado por las leyes de la libertad y no de la causalidad o de la naturaleza. Según este autor, el lenguaje no es un efecto que corresponda a una causa sino más bien el producto

2 La única Lingüistica que podría dar cuenta de nuestro objeto de estudio, el lenguaje, de una manera global y macrótica parecería ser la historia epistemológica de nuestra disciplina. Vid. López García (2001): «Tres modelos lingǘ́sticos y tres actitudes ante el lenguaje», en Fernández, S.\& y M. Hollaender (eds.): Lingüística Cognitiva y Lingüislica Percetiva: algunas aplicaciones al español, Spansk-Romansk Institut, Aarhus Universitet, pp. 41-54, donde se reflexiona sobre la imposibilidad de una ciencia global del lenguaje.

3 Como se hace notar en el trabajo mencionado de López García (2001), en este punto surge inevitablemente la cuestión de cuál será la mejor opción de investigación a la que podemos adscribirnos. Tal y como se ha venido diciendo, todo depende de lo que se quicra averiguar. Dadas las condiciones de relación fenomenológiea que mantenemos con el lenguaje, lo más adecuado parece ser la elección de una actitud ante el lenguaje (pragmatista, formal o semántica) y, a partir de ella, hablar de los matices y aspectos que el lenguaje adquiere en la relación que manticne con nosotros (como pragmatistas, gramáticos o semánticos). Y csto en definitiva es lo que ha dado lugar en nuestra disciplina a la aparición de los distintos modelos explicativos del lenguaje. 
de una interacción (intra o inter-personal). Como afirma Enrique Bernárdez (1999), el lenguaje es un sistema en el que lo que uno haga depende de lo que haga su interlocutor, y lo que este haga depende de lo que haga uno, lanzándose ambos, además, a hacer algo juntos.

Las repercusiones metodológicas de esta manera de entender las leyes que rigen el funcionamiento del lenguaje son notables, pues, desde este punto de vista, se puede confirmar lo mencionado un poco más arriba: el lenguaje no es algo que pueda ser tratado metalingüísticamente de una manera objetiva, es decir, como algo ajeno al investigador, ya que por un lado éste posee el conocimiento del objeto debido a que el objeto forma parte de él, y por otra parte, el objeto de estudio se construye a medida que el investigador va tomando conciencia de él.

Efectivamente, cuando hablamos de lenguaje lo hacemos desde nuestra condición de usuarios y simultáneamente como estudiosos de su naturaleza. Aunque estos dos tipos de conocimiento no pueden equipararse, el hecho de ser hablantes maternos de nuestra lengua nos permite emitir y comprender enunciados nuevos continuamente. No necesitamos estudiar gramática para decir o entender a alguien cuando manifiesta que el lunes es el peor día de la semana.

Por otra parte, como decimos, el objeto lenguaje se va construyendo a medida que e1 investigador va tomando conciencia de él, es decir, el lenguaje adquiere todos aquellos valores, aspectos y funciones que el interés del lingüista va descubriendo. Lo mismo podria decirse de otros objetos de estudio pertenecientes a otras disciplinas. Un cuadrado, por ejemplo, lo será en tanto el interés del geómetra sea averiguar la medida de sus lados, pero se transformará en un cubo cuando le interese el volumen que cs capaz de contener.

E1 lenguaje, desde este punto de vista, no es sólo lo que es por sí mismo, sino también lo que vemos en él. Esto explica la idea fenomenológica de que el lenguaje se construya como objeto de estudio a medida que nosotros, como investigadores, vamos tomando conciencia de él. La perspectiva del fenómeno no le pertenece sólo al objeto ni sólo al sujeto, sino que su esencia resulta de la relación que mantiene el objeto con el sujeto. De esta manera se puede comprender con facilidad que las leyes perceptivas expliquen adecuadamente el hecho conocido de la percepción de un mismo objeto como dos objetos diferentes, incluso para un mismo observador si introduce una tensión determinada cn la visión.

Paralelamente podriamos decir que el lenguaje puede ser simultáneamente un instrumento de comunicación (para la Gramática Funcional), un sistema formal que refleja la organización mental (para la Gramática Generativa), o un sistema cognitivo representativo de las escenas del mundo y de los valores situacionales (para la Gramática Cognitiva), dependiendo de cuál sea la actitud que el investigador adopte ante el lenguaje. $Y$ todo ello se puede decir de nuestro objeto, todo ello es acertado, aunque eso sí, parcialmente acertado.

Actualmente, en nuestra disciplina se acepta ampliamente la necesidad de contemplar el lenguaje como algo en estrecha relación con el investigador o, 10 que es lo mismo, con el metalenguaje que utiliza para describirlo. Es decir, la palabra rama no es únicamente lo que refiere (el objeto), sino también un detcrminado elemento del lenguaje que tiene una forma, una función y un significado en una determinada lengua a través del cual el hablante verbaliza una determinada cscena de la realidad. El lenguaje es un sistema secundario de 
representación de la realidad; el primario sería la percepción directa ${ }^{4}$. Para nosotros, hablantes de español, la palabra rama conduce al concepto árbol, pero un hablante de lenguas amerindias podría comprender extremidad, es decir, un concepto más amplio que le permite aludir al referente $a ́ r b o l$, pero también a su propio cucrpo, o a cualquier elemento que derive de una zona nuclear (central) y no periférica.

Siguiendo los primeros planteamientos de la Teoria de Prototipos (Rosch 1973, Lakoff 1972, Fillmore 1975), sabemos que existe una conexión entre la realidad objetiva y los conceptos con los que el ser humano categoriza dicha realidad, de tal manera que construimos la imagen categorial seleccionando entidades especialmente representativas que constituyen el centro o prototipo de dicha entidad, siendo posible establecer asimismo una periferia o estructura en la que se situarían aquellas entidades con una correspondencia tan sólo parcial respecto a la muestra representativa. Hay, por tanto, grados distintos de pertenencia a la categoría.

Posteriormente, la evolución de la teoría profundiza en su vertiente lingüística planteando la existencia de un principio de molivación según el cual la designación de un objcto de la realidad mediante un signo lingüístico obedece a la familiaridad de la entidad en cuestión (Wittgenstein 1953, Geraerts 1987, 1988). En este sentido, la relación entre los miembros de las categorías se establece a partir de algunas propiedades de algunas entidades. La implicación directa que se deriva de esta afirmación es que el principio que establecía la exigencia de poseer rasgos necesarios y suficicntes a las entidades para pertenecer a determinada categoria ya no es de obligado cumplimiento.

Similarmente, en Lingüística Perceptiva se identifican dos tipos de unidades en el lenguaje para referirse a las escenas del mundo que se pretende verbalizar, independientemente

4 Esta afirmación merece una consideración más amplia: en este trabajo asumimos que los seres humanos disponemos de un sistema primario (analógico) de percepción, esto es, un sistema visual y un sistema auditivo (también táctil, gustativo y olfativo, pero estos no son tan relevantes en el lenguaje cono los anteriores) de percepción de datos que son captados directamente por dichos sistemas perceptivos y comprendidos por nuestro sistema cognitivo, el cual los organiza en forma de imágenes mentales que convierte en lenguaje siguiendo cánones de naturaleza linguística. Ignoramos si se trata de innatismo, pero sí pensamos que la condición lingüística de las imágenes mentales debe de ser previa a su concreción en una lengua cualquiera. También nuestra condición de seres humanos es previa a la concreción de los datos del genoma humano en la persona que luego seremos. Aunque haya quien para ver un ser humano necesite ver unos brazos, una cabcza, unas picrnas... los datos contenidos en el sistema genético incluyen previamente información de carácter humano. Naturalmente cada lengua tiene sus propias formas de concretar los datos de naturaleza lingilistica: unas utilizan el canal oral, es decir, el sonido, mientras que otras utilizan el visual para hacer lo mismo, esto es, verbalizar las escenas del mundo que el hablante tiene representadas mentalmente como imágenes mentales de naturaleza lingüistica. Todo lo cual nos lleva a afirmar que el lenguaje es un sistema primario en cuanto a sus componentes sonoro o visual y semántico, pero la digitalización de esos datos analógicos convierte a las lenguns en sistemas codificados, en sistemas secundarios de percepción de la realidad. Precisamente esto es lo que hace posible que su gramática sea formalizable en reglas, cuestión en la que está empeñada la granática generativa desde finales de los años cincuenta. En todo caso nuestra actitud perceptivista nos lleva a partir del sujeto cognoscente para dar cuenta del mundo y entonces la facultad lingüistica es previa a la digitalización de los datos, micntras que aqucllos invcstigadores que no scan perceptivistas partirán de la realidad del mundo y pensarán que el lenguaje es un sistema que lo representa, y esto, desde nuestro punto de vista, no es otra cosa que un cognitivismo mal entendido. En Veyrat (2003) nos ocupamos más ampliamente de la necesaria complementariedad de los enfoque cognitivista y perceptivo, asumiendo como punto de partida que, si bien el cognitivismo busca la fundamentación cognitiva del lenguaje, el perceptivismo centra su atención en investigar el fundamento lingüistico de la cognición, y con esta complementación, la Lingüística Perceptiva se propone alcanzar, entre otras cosas, una explicación global del binomio pensamiento-lenguaje que caracteriza al ser humano. 
de la categoría gramatical que cada lengua les adscriba ${ }^{5}$ : unidades constitutivas y unidades relacionales (López García, 1977). Las unidades constitutivas son aquellas que tienen existencia independiente y establecen nudos desde el punto de vista dc su sentido, mientras que las unidades relacionales necesitan apoyarse en otras para completar su sentido y por lo tanto aparecerán ligadas siempre a otros elementos.

Tanto la clasificación cognitiva de las unidades en nucleares y periféricas como la perceptiva en constitutivas y relacionales, propician la idea de considerar el espacio categorial como un universo en el que se reconoce un espacio interior y un espacio exterior, así como una frontera que limita a ambos y que, por lo tanto, puede pertenecer bien al espacio interno, bien al externo, dependiendo del punto de vista que adopte el observador. Ciertamente, un espacio queda delimitado tanto si ponemos un cerco para señalar nuestra propiedad desde dentro como si nuestros vecinos acotan sus respectivos dominios para señalar sus posesioncs, solo que de esta manera mis límites quedan establecidos naturalmente, es decir, mi espacio surge espontáneamente a partir de los límites impuestos por mis convecinos.

\section{El VerRo COMO UNIVERSO CATEGoRIAL}

Una vez expuestos los fundamentos perceptivos que nos permiten considerar la categoría verbo como un espacio donde podemos establecer una frontera, nos disponemos a presentar el modo de obtener una clasificación de los verbos de nuestra lengua que nos proporcione una comprensión adecuada de su funcionamiento como principales o como auxiliares.

En Topología, disciplina ocupada de la descripción de los espacios, cuando queremos ordenar los elementos dentro de un espacio para poderlo medir, debemos introducir un criterio clasificador de los elementos integrantes de dicho espacio, es decir, introducimos una topología determinada. Hay numerosos ejemplos de esto en la vida cotidiana, pues lo mismo sucede cuando pretendemos organizar nuestro armario: podemos adoptar cualquiera de los criterios siguientes dependiendo de cuál sea nuestra necesidad organizativa: prendas largas/ prendas cortas, o bicn prendas de vestir/ prendas de diario, o incluso prendas de invierno prendas de verano... etc. No olvidemos que siempre tendremos alguna prenda que pueda cumplir tanto con uno de los criterios como con el otro; serían prendas «fronterizas».

Paralelamente, en el espacio categorial del verbo deberemos introducir el criterio clasificador apropiado para nuestros intereses descriptivos. Nuestra intención aquí es explicar los motivos por los que unos verbos de nuestra lengua siempre aparecen referidos a otras acciones, es decir, en uso auxiliar y nunca como principales (soler, haber), otros siempre son utilizados en su función de principales y nunca como auxiliares (soñar, comer...) y otros parecen ser arbitrariamente empleados unas veces como verbos autónomos y plenos semánticamente, es decir, principales, pero en otras ocasiones su uso refleja una falta de autonomía y la consiguiente dependencia de otra forma verbal no personal (enpezar, acabar, $i r$, venir, echar, ...), lo culal indica su uso como auxiliares en tales casos.

5 Según afirma López García (1977), la oposición UC/UR es lingüistica pero no es gramatical, es decir, no se cstablece mediante el concurso de la estructura de las lenguas, y por lo tanto la inclusión de determinadas palabras de las lenguas en uno u otro tipo de unidades no está condicionada por su pertenencia a un rango categorial determinado. En español, los verbos meteorológicos son constitutivos (lhueve, nieva, no necesitan apoyarse en el sujeto), pero en francés, por ejemplo, son unidades relacionalcs (il pleut, il neige). 
El criterio clasificador que necesitamos nos viene dado por la observación de los rasgos que distinguen las formas verbales cuando aparecen en construcciones léxicas y cuando lo hacen en construcciones pcrifrásticas de nuestra lengua ${ }^{6}$. Es decir, en aquellas estructuras verbales complejas donde verbos como acabar o ir aparecen autónomamente (pudiendo por tanto seleccionar sus propios argumentos) y no modifican aquella acción representada por una forma verbal no personal que le acompaña, estaremos ante un uso principal de los verbos en forma conjugada:

(1) Antonio ya ha acabado de estudiar la carrera (ha acabado los estudios)

(2) Paula ha ido a llevarle la comida a la abuela (se ha desplazado para eso)

Sin cmbargo, cuando en las estructuras verbales complejas los verbos conjugados modifiquen temporal, modal o aspectualmente la acción señalada por la forma no personal y dependan de ella para terminar de configurarse como formas verbales, estaremos ante un uso auxiliar de los verbos en cuestión y por lo tanto, ante una forma verbal perifrástica (no ya una construcción léxica de infinitivo, participio o gerundio):

(3) Enrique acaba de Ilegar al Rectorado

(4) El boli ha ido a caer justo debajo del mueble

Podemos ahora caracterizar los elementos del universo verbal distinguiendo aquellos que poseen los rasgos [tautónomo -modificador], que son los verbos en uso pleno o principal, de aquellos que se definen por los rasgos inversos [-autónomo +modificador], verbos en uso auxiliar.

Por otra parte, tendremos también distinguidos los verbos fronterizos ${ }^{7}$, es decir, aquellos que participan a la vez de ambos rasgos: [ \pm autónomo \pm modificador]. Este espacio fronterizo alberga a aquellos verbos que dan cuenta de la situación intermedia surgida al enfrentar el

6 El problema de la identificación de los verbos auxiliares es complejo y demasiado cxtcnso para abordarlo en este trabajo. Las prucbas o tests que se aplican a los verbos para determinar su carácter pleno o auxiliar han sido establecidas a partir de la observación de su comportamiento sintáctico y/o semántico. Uno de los trabajos más importantes en este campo es el de Fontanella de Weinberg (1970). Vid entre otros los trabajos de Fernández de Castro (1990), Veyrat Rigat (1993), Gómez Torrego, L. (1999).

7 Coseriu (1978) propone trasladar a los verbos la conocida distinción del gramático Vives entre nombres denominativos y nombres adjetivos, pues hay unidades verbales que no representan una clasificación primaria de la realidad, sino determinaciones secundarias releridas a otras acciones, y engloba bajo la designación de verba adiecta a verbos como poder, queres, deber, camenzar, continuar, terminar... porque funcionan únicamente en relación con otras acciones y por tanto su significado léxico existe únicamente en tanto que se refieren a otro verbo y 10 modifican, esto es, significan algo sólo en relación con el cómo de esta aprehensión. En palabras de Dietrich (1973:77): «representan, al igual que los «substantiva adiecta» en relación con los sustantivos, una posibilidad funcional dentro de la categoría léxica «verbow mediante la cual se deternina la clase de la aprehonsión de la realidad extralingúística, no su aprehensión primaria misma». Desde nuestro punto de vista, los verba adiecta son los verbos que localizamos en la frontera del espacio verbal, simultaneando la capacidad de ser usados como auxiliares y como principales. Debido a cllo, hemos incluido cn cste espacio verbos como empezar, comenzar, acabar; terminar y poder, que son los que cumplen estas condiciones. E incluimos verbos como querer y deber entre los adherentes a auxiliares, es decir, entre aquellos verbos que en cada una de sus ocurrencias determinan su uso como auxiliares por no aparccer como principales: «quiero leer un rato», «debe estudiar más a fondo» (Cf, el uso principal en «quiero más café», «debo 20 euros». Recordemos que el uso principal se caracteriza por marcar al verbo con los rasgos [-modificador tautónomo]). 
uso principal al uso auxiliar de los verbos, mostrándose una relación de contigüidad, es decir, que se establece entre ellos un continum bien desde una condición de principalidad hacia la auxiliaridad, bicn desde una condición de auxiliaridad hacia la principalidad. En otras palabras, en la frontera del espacio verbal habrá elementos que contengan rasgos propios de los auxiliares y elementos que tengan rasgos de los principales.

Esta condición doble la muestran bien verbos como empezar, acabar, comenzar, terminar, poder... Son verbos que simultáneamente actúan o pueden actuar como modificadores y como no-modificadores, como autónomos y como no-autónomos. Veamos algumos ejemplos:

(5) Empieza la sesión / Empieza a recuperar el habla

(6) Acaba la tarea / Acaba de llegar a la estación

(7) Tomás puede con todo / Su discurso puede significar el fin de la crisis

(8) Jaime terminó la ensalada / Al final terminó por encontrar bien hasta eso

Cabe, no obstante, introducir un matiz dentro de este espacio limítrofe para ubicar aquellos verbos que, disponiendo de esa doblc condición, es decir, siendo de naturaleza fronteri$\mathrm{za}$, sin embargo su esencia definitiva como auxiliar o principal queda establccida solamente cuando se determina la frontcra desde el espacio interior (y entonces, desde el punto de vista que hemos adoptado en este trabajo, actúan como verbos auxiliares) o bien desde el espacio exterior ( $\mathrm{y}$ en tal caso actúan como verbos principales). La adherencia es una tendencia de los elementos fronterizos hacia cualquiera de los dos conjuntos, el nuclear (función auxiliar cn nucstro caso) o el complementario (en este estudio, función principal), pero no implica comportamiento sintagmático, sino que explica la capacidad que en teoría tienen estos verbos situados en la frontera para actuar como principales o como auxiliares.

Para poder describir el paradigma funcional del verbo y reconocer los elementos que lo constituyen, nos vemos obligados a considerar que estas unidades no están dadas de antemano, sino que se definen tanto por lo que son como por lo que no son, o lo que es lo mismo, se definen al enfrentarse con aquellas unidades que constituyen su conjunto complementario.

Debido a ello, la caracterización de los elementos adherentes corresponde a la caracterización del conjunto hacia el que queremos señalar que ticnden o se aproximan dichos elementos. Si la tendencia es hacia los [+auxiliares puros] estarán marcados en cada una de sus ocurrencias con alguno de los rasgos [+modificador, -autonomía]; si la tendencia es hacia los [ + principales puros] lo estarán con alguno de los rasgos [-modificador, tautonomía].

Sin embargo, para que pertenczcan a la Lengua como [tauxiliares puros] tendrán que ser usados sintagmáticamente caracterizados con ambos rasgos [+modificador -autonomía]. Si por el contrario quieren pertenecer a la Lengua como [ + principales puros] tendrán que ser utilizados sintagmáticamente con los rasgos de los [+principales puros], es decir [-modificador tautonomia]. Los elementos adherentes necesitan ambos rasgos sólo cuando se realizan en la cadena. Como elementos adherentes, en el paradigma sc caracterizarán en función de su tendencia hacia uno u otro de los conjuntos nuclear o complementario.

Para poder hablar de ellos tenemos que poder constituir un conjunto cerrado con ellos. Este conjunto cerrado estará formado por aquellos verbos que son el núcleo y aquellos elementos de la frontera que se aproximan a ćl, es decir que en cada entomo en que aparecen contienen alguna marca que justifique su adherencia al núcleo. Nos referimos a los casos de 
verbos como ir, venir, volver, echar, ponerse, romper, dar, ser, estar, deber, querer, necesitar. Tenemos así dos clases de verbos que se denominan adherentes:

A) verbos que muestran adherencia a la auxiliación debido a que los límites de su actuación como verbos están impuestos desde dentro, es decir, desde el espacio interior del universo verbal, que en nuestro caso corresponde a los verbos auxiliares puros. Se trata de verbos como ir, venit, volver, echar, ponerse, romper, dar...que en todos los entornos en que aparecen como tales contienen los rasgos que justifican su tendencia a la auxiliación, es decir, modifican la acción y dependen de ella para constituirse como verbos:

(9) La moneda fue a dar contra el jarrón

(10) Mi primo vino a decir que no le caías bien

(11) José vuelve a sentir molestias en el estómago

(12) La enfermera echó a correr escaleras abajo

(13) Carlos se puso a escribir rabiosamente

(14) Mi madre rompió a llorar cuando lo supo

(15) $A$ mi amiga le dio por bailar salsa el año pasado

B) verbos que muestran adherencia a la principalidad o autonomía debido a que la esencia de su actuación como verbos está impuesta desde fuera, desde cl cspacio cxtcrior, como sucede con ser, estar, deber, querer, necesitar... De la misma manera, estos verbos contienen Ios rasgos que justifican su adherencia a la principalidad en todos los entornos en los que aparecen como tales:

(16) Nacho es químico

(I7) Ahora mismo estoy de pie

(18) Joaquín debe $100 €$ en la tienda

(19) Teresa quiere un coche mevo

(20) El cocinero necesita la sal y la pimienta

De este modo los verbos quedan definidos en su función auxiliar o principal por lo que no son en esas apariciones. El espacio de adherencia implica que hay verbos que pueden llegar a ser considerados principales aunque tienden hacia la auxiliación, como sucede con los verbos ser; estar; querer, deber, necesitar... Veamos el contraste entre ambos usos:

(21) Nacho es quimico / Nacho es detenido por la policia

(22) Ahora mismo estoy de pie /Ahora mismo estoy hablando con mi hijo

(23) Teresa quiere un coche nuevo / Teresa quiere bailar contigo

(24) Joaquín debe $100 €$ en la tienda / Joaquin debe llegar a tiempo

(25) Fl cocinero necesita la sal y la pimienta' El cocinero necesita beber agua

Y simultáneamente, este espacio de adherencia implica también que hay verbos que pueden llegar a ser considerados auxiliares a pesar de que tienden hacia la plenitud: dar; volver, ir, venir, echar, romper...

(26). Iulio le dio 1006 al tenders / A . Fulio le dio por hailar salsa

(27) Antonio vuelve a Madrid / Antonio vuelve a sentirse peor

(28) El tren viene a Valencia / El tren viene a ser Io mismo que el autobus

(29) Ignacio iha al médico / Ignacio iba a contárselo indo 
(30) La enfermera echa sal a la carnel La enfermera echa a correr sobresaltada

(31) Luisa rompió un vaso./Luisa rompió a llorar desconsoladamente

En estos casos la frontera es un espacio que surge de manera sustractiva, de donde resulta que los verbos que actúan como plenos o principales lo hacen cuando y porque no son auxiliares, y a la inversa, los verbos que actúan como auxiliares lo hacen cuando y porque no son principales.

\section{Clasificación perceptiva det. paradigma funcional del verbo}

El fundamento gestáltico de nuestro modelo lingüístico-perceptivo ${ }^{8}$ pcrmite trabajar el universo verbal tomando como espacio interno (o figura, y por tanto, estamos refiriéndonos al conjunto descrito) a cualquiera de los dos usos sintáctico-semánticos quc tienen los verbos en nuestra lengua (principal o auxiliar) y dejar el otro como espacio externo (o fondo, y por tanto conjunto descriptor); y a la inversa.

Sin embargo, debido a nuestro interés en este trabajo por el uso auxiliar constante, así como por el uso auxiliar esporádico de algunos verbos fundamentalmente considerados principales y la condición fronteriza de algunos verbos, interpretamos este espacio (el interno) como el conjunto de términos verbales auxiliares que constituyen el conjunto cerrado o descrito, y tomamos los términos verbales plenos del conjunto exterior como conjunto abierto o descriptor, considerando igualmente que los verbos que se encuentran en la frontera explican la simultaneidad en la capacidad de los verbos fronterizos para tener un comportamiento indistintamente auxiliar o principal, dependiendo únicamente de la intención comunicativa del hablante, que será quien seleccione finalmente la forma de su cnunciado cn virtud de la capacidad potencial que tienen las formas del paradigma verbal para actuar en una u otra función.

La visualización del planteamiento topológico expuesto en este trabajo nos presentaría la siguiente distribución espacial del universo verbal; sicndo

A.- El espacio interno donde están contenidos los verbos anxiliares puros

B.- El espacio externo donde se sitúan los verbos plenos que nunca son auxiliares

C.- El espacio fronterizo donde se localizan los verbos que muestran la doble naturaleza auxiliar y principal y el espacio de adhercncia que garantiza que todo verbo (excepto los auxiliares puros como haber y soler) puede actuar como principal o como auxiliar. No olvidemos que este espacio dc adherencia es un espacio dinámico que legitima el movimiento de los elementos adherentes hacia una u otra función.

Figura 1

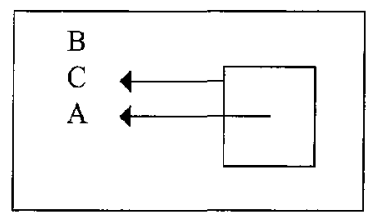

8 Para los conceptos topológicos, así como para el resto del planteamiento matemático de la lingüística perceptiva, vid. López García (1980, 1989). 
Aplicando los presupuestos que hemos desarrollado en las páginas anteriores, y observando nuestra lengua, vemos que cn español podemos encontrar:

1.-Verbos auxiliares puros: verbos del grupo A [-autónomos +modificadores]: haber, soler...

2.-Verbos principales puros: verbos del grupo B [+autónomos -modificadores]: beber; volar, soñar, saltar... que, al menos hasta la actualidad, nunca han mostrado rasgos de auxiliación ni tendencia hacia el funcionamiento del conjunto complementario auxiliar.

3.-Verbos fronterizos: verbos del grupo C [ \pm autónomos tmodificudores]: empezar, acabar; comenzar, terminar, poder... aquellos verbos que aparecerán en situaciones intermedias, que no pueden ser limitados unívocamente, es decir que participan de los dos rasgos al mismo tiempo.

4.-Verbos adherentes: [ \pm autónomos, \pm modificadores]; ser, estar, querer, deber, necesitar, continuar, ir, venir, dar; volver, echar, ponerse, romper... son aquellos verbos que en cada enturno en que aparecen contienen siempre algún rasgo por los que se caracterizan como parte del conjunto al que tienden.

Nuestro punto de partida para esta clasificación es, como hemos señalado, la observación de lo que sucede en la lengua española. Como sabemos, las acciones, así como los estados y los procesos son nombrados por unidades que llamamos verbos: ser, estar; haber, tener, soler, correr, volar, saltar, soñar, beber, empezar, acabar, dar, ir venir, querer, poder, deber, necesitar...Por lo tanto, en principio todos los verbos deberian poder representar acciones de una manera autónoma, como es el caso excepto para los verbos soler y haber:

(32) yo soy la profesora

(33) estoy en Valencia

(34) tengo tres hijos

(35) correré cinco kilómetros

(36) soñé que me querias

(37) empieza la fiesta

(38) por fin terminó la carrera

(39) le dio un libro

(40) Toni fue a Huelva

(41) ayer vino Marta

(42) quiero tarta de postre

(43) te debo cien euros

(44) necesito un piso nuevo...

*(45) yo suelo la cocina

*(46) Maria habia la ropa

Pero lo que se constata en nuestra lengua es que algunos de ellos, por evolución o por su propio contenido léxico, no consiguen una representación autónoma y se refieren siempre a otras acciones, como sucede con haber y soler (son los que consideramos aquí en el espacio interno, auxiliares puros):

(47) he volado

(48) suelo comer deprisa 
Otros sin embargo, por su contenido léxico funcionan simultáneamente como verbos plenos y como auxiliares: empezar, acabar, terminar, comenzar, poder (son los que situamos como verbos fronterizos):

(49) empezó a asomar la cabeza / empezó el parto

(50) acaba de llegar a clase / acaba la cuenta atrás

(51) terminé de redactar el cuento / terminé el dibujo

(52) comenzaba a sonar su nombre con fuerza / comenzaba la celebración

(53) puedo hablar más alto / puedo con todo

Finalmente, existen otros verbos que, disponiendo de la dualidad funcional que singulariza a los fronterizos, cuando aparecen en un entorno tendente a la auxiliación, se confirman como auxiliarcs, como sucede con ser y estar, querer, deber y necesitar, ir, venir, volver; dar, echar, romper, ponerse... Son los verbos que hemos localizado en cl cspacio de adherencia:

(54) los ladrones son detenidos por la policia

(55) estoy redactando el trabajo

(56) queria llamar a Toni

(57) debíu valer algo menos

(58) necesitó hablar con alguien

(59) la moneda fue a caer bajo el armario

(60) vino a decir lo mismo que tis

(61) volverá a jugar mañana

(62) le dio por estudiar Químicas

(63) echó a correr en cuanto pudo

(64) rompio a llorar desconsoladamente

(65) se puso a gritar como una loca...

Por lo tanto, desde el punto de vista perceptivo-topológico llegamos a la siguiente clasificación semántico-sintáctica de las unidades pertenecientes al paradigma funcional de la categoría verbo:

1.- Verbos auxiliares puros: son aquellos verbos que no aparecen nunca como acciones independientes, sino que se refieren siempre a otra y la modifican temporal, modal o aspectualmente: haber, soler

2.- verbos principales puros: no aparecen nunca, en el estado actual de nuestra lengua, como modificadores de otra acción y tienen autonomía sintáctica: beber, comer; soñar, saltar, correr, volar, enseñar...

3.- verbos fronterizos: en su naturaleza está el ser simultáncamente auxiliares y principales: empezar, acabar, terminar, comenzar, poder. Debido a esta dualidad resulta difícil reconoccr su comportamiento y solamente podremos acceder a él atendiendo a la estructura de la construcción en la que intervengan ${ }^{9}$.

4.- verbos adherentes: son aquellos que se confirman como auxiliares no por sí mismos, sino porque en su concreción sintagmática no actúan como principales. El espacio de ad-

9 En otro lugar nos hemos ocupado del tema revisando la ambigiedad de algunas estrueturas perifrásticas y planteando una posible solución. Vid. Veyrat (1994). 
hesión se crea por contraste, y así, dentro de esle grupo de verbos, auxiliar es aqucl que no se comporta como principal, y a la inversa, principal será aquel que no muestre un comportaniento de auxiliar: ser, estar, querer, deber, necesitar; continuar, ir, venir, dar, volver, echar, rompes, ponerse...

\section{ReFFrenclas BidLiográHICAS}

Bcrnárdez, E. (1999): ¿Qué son las lenguas?, Madrid, Ed. Alianza

Coserin, E. (1978): «Semántica y Gramática», en Coseriu, E. (1978): Gramática, semántica y universales. Estudios de lingüística funcional, Madrid, Ed. Gredos, págs. 128-147

Coseriu, E. (1981): Lecciones de Lingüistica General, Madrid, Ed. Gredos

Dietrich, W. (1973): El aspecto verbal perifrástico en las lenguas ramánicas. Estudios sobre el actual sistema verbal de las lenguas románicas y sobre el problema del origen del aspecto verbal perifrástico, Madrid, Ed. Gredos

Fernández de Castro, F. (1990): Las perifrasis verbales en español. Comportamiento sintáctico e historia de su caracterización, Departamento de Filologia Española, Universidad de Oviedo

Fernández de Castro, F, (2003): «El lugar de las perifrasis verbales en la descripción de las lenguas: los verbos auxiliares y la determinación del verboy, en Pusch, C.D. y Wesch, A. (2003): Verbalperiphrasen in den (ibero-)romanischen Sprachen, Helmut Buske Vcrlag, Hamburg, págs. 11-22

Fi1lmore, Ch.,E. (1975): «An alternative to Checklist Theorics of Meaning», Proceedings of the 1st Annual Meeting of the Berkeley Linguistic Society, págs. 123-131

Fontanella de Weinberg, B. (1970): «Los auxiliares españoles», AlL 10, págs. 61-73

Gómez Torrego, L. (1999): «Los verbos auxiliares. Las perífrasis verbales de infinitivo», en Bosque, I. y V. Demontc (eds.) (1999): Gramática descriptiva de la lengwa española, Real Academia Española, Colección Nebrija y Bello, Madrid, Espasa, págs. 326-342

Geraerts, D. (1987): «Prototypicality as a prototypical notion», Communication et Cognition, 20, págs. 275-291

Geraerts, D. (1988): «On Necessary and Sufficient Conditions», Journal of Semantics, 5, págs. 275291.

Lakoff, G. (1972): «Hedges, a study in Meaning Criteria and the Logic of Fuzzy Concepts», Proceedings of the Chicago Linguistic Society, 8 , págs. 183-228

López García, A. (1977): Elementos de Semántica Dinámica, Zaragoza, Ed. Pórtico

López Garcia, A. (1980): Para una gramática liminar, Madrid, Ed. Cátedra

López García, $\Lambda$. (1989): Fundamentos de Lingüistica perceptiva, Madrid, Ed. Gredos

Olbertz, Hella (1998): Verbal periphrases in a functional grammar of Spanish, Functional Grammar series; 22, Berlin; New York: Mouton de Gruyter

Rosch, E. (1973): «On the intcrnal structure of perceptual and semantic catcgories», en T.E. Moore (ed.): Cognitive Development and the Acyuisition of Language, Nueva York, Londres: Academic Press, págs. 111-144

Vcyrat Rigat, M. (1993): Aspecto, perifrasis y auxiliación: un enfoque perceptivo, LynX,: a monographic series in Linguistics and World Perception, annexa 6, Valeneia

Veyrat Rigat, M. (1994): «La perifrasis verbal «acabar de + infinitivo» y la resolución de su ambigüedad», en Vox Romanica, 53, págs. 238-252

Veyrat Rigat, M. (1997): «Los verbos auxiliares y las perifrasis verbales», en Revista de Español Actual, $\mathrm{n}^{\circ} 67,1997$, págs. $37-50$

Veyrat Rigat, M. (1998): «Concepción fenomenológico-perceptiva del lenguaje», en Cifucntes Honrubia, J.L. (1998): Estudios de Lingüistica Cognitiva, I, Universidad de Alicante, págs 353-363

Veyrat Rigat, M. (2001): «QQué es una perífrasis verbal?», en Fernández, S, y M. Hollaender (eds.): Lingüistica Cognitiva y Lingüistica Perceptiva: algunas aplicaciones al español, Spansk-Romansk Institut, Aarhus Universitet, págs. 1-11. 
Veyrat Rigat. M. (e.p.): «Las alteraciones de la comunicación», Revista de Investigación Lingizística, Universidad de Murcia

Wittgenstein, L, (1953): Philosophical Investigations, New York: The McMillan Co. 